\title{
Portuguese Consensus on the Diagnosis, Prevention and Treatment of Anaemia in Inflammatory Bowel Disease
}

\author{
Consenso Português sobre o Diagnóstico, Prevenção e \\ Tratamento da Anemia na Doença Inflamatória Intestinal
}

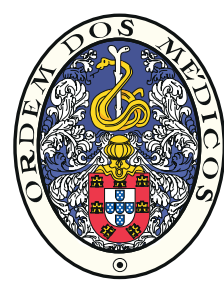

Fernando MAGRO $\triangle^{1-3}$, Jaime RAMOS ${ }^{1,4}$, Luís CORREIA ${ }^{1,5}$, Paula LAGO ${ }^{1,6}$, Paula PEIXE ${ }^{1,7}$, Ana Rita GONCALVES ${ }^{1,5}$, Ângela RODRIGUES ${ }^{1,6}$, Catarina VIEIRA ${ }^{1,5}$, Daniela FERREIRA' ${ }^{1,6}$, João PEREIRA DA SILVA ${ }^{1,8}$, Maria Ana TÚLIO ${ }^{1,7}$, Paulo SALGUEIRO ${ }^{1,6}$, Samuel FERNANDES ${ }^{1,5}$

Acta Med Port 2016 Feb;29(2):144-156 - http://dx.doi.org/10.20344/amp.6058

\section{ABSTRACT}

Introduction: Anaemia can be considered the most common extra-intestinal manifestation in inflammatory bowel disease. Nevertheless, anaemia is often under-diagnosed and under-treated both in adults and children with inflammatory bowel disease. Herein, we report the consensus statements on the management of anaemia in inflammatory bowel disease developed by the Portuguese Working Group on Inflammatory Bowel Disease (known as Grupo de Estudo da Doença Inflamatória Intestinal - GEDII) to aid clinicians in daily management of inflammatory bowel disease patients.

Material and Methods: A comprehensive literature review was conducted in order to prepare consensus statements on the following topics: (1) prevalence and diagnosis of anaemia in inflammatory bowel disease, (2) iron supplementation for the prevention of anaemia in inflammatory bowel disease and (3) treatment of anaemia in inflammatory bowel disease. The final statements for each topic were discussed at a consensus meeting and rated according to the Oxford Centre for Evidence-Based Medicine 2011 Levels of Evidence. Consensus: It was concluded that anaemia has a high incidence and prevalence in inflammatory bowel disease, particularly in those with active disease and hospitalised. Patients with anaemia had decreased quality of life and frequently complained of fatigue. Absolute indications for intravenous therapy should be considered: (1) moderate to severe anaemia (haemoglobin < $10.5 \mathrm{~g} / \mathrm{dL}$ ) or clearly symptomatic anaemia; (2) previous intolerance to oral iron supplements; (3) inappropriate response to oral iron; (4) active severe intestinal disease; (5) need for a quick therapeutic response (e.g. surgery in the short term); (6) concomitant therapy with erythropoiesis-stimulating agent; and (7) patient's preference.

Keywords: Anemia/diagnosis; Anemia/drug therapy; Anemia/prevention \& control; Evidence-Based Practice; Inflammatory Bowel Diseases; Portugal.

\section{RESUMO}

Introdução: A anemia pode ser considerada a manifestação extra-intestinal mais comum na doença inflamatória intestinal. Ainda assim, a anemia é subdiagnosticada e subtratada tanto em adultos como em crianças com doença inflamatória intestinal. Assim, apresentamos o consenso alcançado pelo Grupo de Estudo da Doença Inflamatória Intestinal - GEDII relativamente à gestão da anemia na doença inflamatória intestinal, com o objetivo de facilitar o acompanhamento clínico dos doentes com doença inflamatória intestinal. Material e Métodos: Foi conduzida uma revisão exaustiva da literatura, por forma a preparar statements de consenso nos seguintes tópicos: (1) prevalência e diagnóstico de anemia na doença inflamatória intestinal, (2) ferro da prevenção da anemia na doença inflamatória intestinal e (3) tratamento da anemia na doença inflamatória intestinal. Os statements finais para cada tópico foram discutidos na reunião de consenso e classificados de acordo com os níveis de evidência definidos em 2011 pelo Oxford Centre for EvidenceBased Medicine.

Consensos: Concluiu-se que a anemia tem elevada incidência e prevalência na doença inflamatória intestinal, particularmente entre pacientes com doença ativa e hospitalizados. Indicações absolutas para terapia intravenosa devem ser consideradas quando existe: (1) anemia moderada a severa (hemoglobina < 10,5 g/dL) ou anemia claramente sintomática; (2) intolerância prévia à terapêutica com ferro por via oral; (3) resposta inadequada à terapêutica com ferro por via oral; (4) doença intestinal ativa severa; (5) necessidade de resposta terapêutica rápida (e.g. cirurgia a curto prazo); (6) terapêutica concomitante com agente estimulante da eritropoiese; e (7) preferência do paciente.

Palavras-chave: Anemia/diagnóstico; Anemia/prevenção \& controlo; Anemia/tratamento; Doença Inflamatória Intestinal; Portugal; Prática Clínica Baseada em Evidências.

\section{INTRODUCTION}

Depending upon the definition used, anaemia can be considered the most common extra-intestinal manifestation in Inflammatory Bowel Disease (IBD). ${ }^{1}$ Nevertheless, it is

very obvious that anaemia is often under-diagnosed and under-treated both in adults and children with IBD. ${ }^{2,3}$

Anaemia in IBD has often a multifactorial origin, the

1. Grupo de Estudo da Doença Inflamatória Intestinal. Lisboa. Portugal.

2. Departamento de Farmacologia e Terapêutica. Faculdade de Medicina. Universidade do Porto. Porto. Portugal.

3. Serviço de Gastrenterologia. Centro Hospitalar de São João. Porto. Portugal.

4. Serviço de Gastrenterologia. Hospital de Santo António dos Capuchos. Centro Hospitalar de Lisboa Central. Lisboa. Portugal.

5. Serviço de Gastrenterologia. Hospital de Santa Maria. Centro Hospitalar Lisboa Norte. Lisboa. Portugal

6. Serviço de Gastrenterologia. Hospital de Santo António. Centro Hospitalar do Porto. Porto. Portugal.

7. Serviço de Gastrenterologia. Hospital Egas Moniz. Centro Hospitalar de Lisboa Ocidental. Lisboa. Portugal.

8. Serviço de Gastrenterologia. Instituto Português de Oncologia de Francisco Gentil de Lisboa. Lisboa. Portugal.

$\triangle$ Autor correspondente: Fernando Magro.fm@med.up.pt

Recebido: 03 de dezembro de 2014 - Aceite: 16 de dezembro de 2015 | Copyright @ Ordem dos Médicos 2016 
most frequent causes being iron deficiency and anaemia of inflammatory disease. The only population-based cohort study that prospectively evaluated the prevalence of anaemia over 10 years in both forms of the disease versus the general population (IBSEN study) found that the frequency of anaemia varied significantly over time, decreasing globally. Anaemia was more common in Crohn's disease, particularly in women, and was significantly associated with the use of corticosteroids and, above all, with the elevated C-reactive protein (CRP), this highlighting the importance of inflammation in the genesis and maintenance of anaemia. ${ }^{4}$ Finally, other causes such as vitamin B12 and folic acid deficiency are also common but proportionally less common than previously assumed. ${ }^{1}$

The prevalence of anaemia in IBD is high. It is estimated that up to $75 \%$ of patients may have anaemia in the course of their illness, the most common form being iron deficiency anaemia. ${ }^{5}$ Moreover, about $30 \%-90 \%$ of patients with IBD have iron deficiency, ${ }^{6}$ which, even without anaemia, may be of clinical relevance. ${ }^{7}$

The European Crohn's and Colitis Organisation (ECCO) recently published a European consensus to guide the diagnosis, treatment and prevention of iron deficiency and iron deficiency anaemia (IDA) in IBD. ${ }^{8}$ To aid Portuguese clinicians in daily management of IBD patients, the Portuguese Working Group on Inflammatory Bowel Disease (known as Grupo de Estudo de Doença Inflamatória Intestinal - GEDII) set out to developed this sustained, evidence-based consensus paper, tailored for the specificities of the Portuguese clinical practice.

In developing this document, THREE working groups within the GEDII were created to address specific topics. Each working group conducted a comprehensive literature review (PubMed, Scopus and ISI Web of Knowledge) and then prepared the consensus statements on one of the following topics: (1) prevalence and diagnosis of anaemia in IBD, (2) iron supplementation for the prevention of anaemia in IBD and (3) treatment of anaemia in IBD. The strategy to reach the Consensus on the guideline revisions involved seven steps: i) In parallel, the working parties performed a systematic literature review. The evidence level (EL) was graded according to the Oxford Centre for Evidence Based Medicine of 2011 guidance. ii) Provisional guideline statements on their topic were then written by the chairs of the working groups and posted to all groups. Discussions and exchange of evidence from the literature among the working party members was then performed. iii) After the first voting, all consensus statements that did not reach an approval rate above $80 \%$ were revised. iv) On October 2014, the working parties met in Curia to agree upon the statements. Technically, this was done by projecting the statements and revising them on screen, until a consensus was reached. v) Consensus was defined as agreement by $>80 \%$ of participants, termed a Consensus Statement and numbered for convenience in the document. vi) The final document on each topic was written by the chairs in conjunction with their working party. vii) The final text was edited for consistency of style by Fernando Magro. This work was coordinated by Fernando Magro and the three groups were coordinated by Paula Lago, Luis Correia, and Paula Peixe and Jaime Ramos.

\section{Prevalence of anaemia in inflammatory bowel disease

$\begin{aligned} \text { Statement 1: } & \text { The prevalence of anaemia in IBD is high } \\ & (\mathrm{EL} 2) \\ & \text { Agreement: } \mathbf{1 0 0 \%}\end{aligned}$

Statement 2: The prevalence of anaemia is higher in Crohn's disease than in ulcerative colitis (EL 3), higher in hospitalised patients than in ambulatory patients (EL 3 ) and higher in children than in adults (EL 3 )

Agreement: $100 \%$

Statement 3: The main causes of anaemia in IBD are iron deficiency (the most common cause) and chronic disease anaemia, coexisting frequently (EL 3)

Agreement: $100 \%$

Statement 4: The prevalence of anaemia in IBD tends to decrease due to a better control of the inflammatory activity of the disease (EL 3) and a greater implementation of corrective measures of iron deficiency (EL 5) Agreement: $90 \%$

\section{Rationale}

The prevalence of anaemia in IBD varies between $6 \%$ and $74 \% \%^{2-4,9-40}$ with a median of $17 \%{ }^{6}$ The discrepancy between the results of different studies may be explained by the different definitions of anaemia, the characteristics of the study population and the year in which they took place. In the IBSEN study, ${ }^{4}$ a population-based cohort, with a follow-up of 1, 5 and 10 years, evaluated 756 patients with IBD (ulcerative colitis [UC]: 519, Crohn's disease [CD]: 237) and found, at screening, a prevalence of anaemia of $48.8 \%$ in CD and $20.2 \%$ in UC, with the proportion of patients with anaemia decreasing in all cases during the course of the disease with the exception of women with $C D$. An increased CRP level was significantly correlated with the presence of anaemia. In the study of Vijverman et al, ${ }^{36}$ a retrospective cohort, 170 outpatients with IBD were evaluated ( $n=80$ in 1993 and $n=90$ in 2003). A decrease in the prevalence of anaemia from 34\% to $17 \%$ between the 1993 and 2003 cohorts was found. This difference was independent of age, gender, site, duration of the disease and previous surgery. The decrease in the prevalence of anaemia was more significant in patients with CD and moderate anaemia, the only difference between the two cohorts being the wider use of immunosuppressants and infliximab in the 2003 cohort.

In some studies, a higher prevalence of anaemia in patients with CD compared with UC was shown. In a single centre $^{28}$ among 253 IBD patients (136 with CD and 117 with UC), the overall prevalence of anaemia was $30 \%$ (39\% for CD and $20 \%$ for UC), rising to $66 \%$ in hospitalised patients. 
A multivariate logistic regression analysis showed that anaemia was associated with a diagnosis of CD (OR: 2.2), with the need for corticosteroids (OR: 3.9), with the need for hospitalisation (OR: 3 ) and with an increased sedimentation rate (OR: 1.04). However, patients with $C D$ had higher disease activity, greater need for corticosteroids and hospitalisation, which may explain the higher prevalence of anaemia. Bager et al, ${ }^{9}$ in a multicentre cohort with 429 IBD patients, reported an overall prevalence of anaemia of $19 \%$, higher in patients with CD than in patients with UC ( $p=$ 0.01 ). The aetiology of anaemia was iron deficiency in $20 \%$ of the cases, in $12 \%$ chronic disease anaemia, and in $68 \%$ a combination of both. Less than $5 \%$ of the patients had a deficit of folic acid or vitamin B12. Patients treated with an inhibitor of tumour necrosis factor (TNF)-alpha had a higher prevalence of anaemia ( $25 \%$ vs $5.4 \%$ ), which was not observed with other drugs, namely immunosuppressants, corticosteroids and aminosalicylates. This association may be related with the higher severity of the disease. There were no differences in the prevalence of anaemia as regards the location of the disease in $C D$ and its extent in UC. It was also found that the presence of anaemia in outpatients was associated with the need for hospitalisation (19\% vs $5.7 \%, p=0.015) .{ }^{33}$ Ott et al, ${ }^{3}$ in a population-based study with 279 IBD patients (183 with CD, 90 with UC and 6 with unclassified colitis), found a prevalence of anaemia of $32 \%$, of which $70 \%$ had iron deficiency. The prevalence of severe anaemia (haemoglobin $<10 \mathrm{~g} / \mathrm{dL}$ ) was higher in patients with UC compared with CD. In a systematic review, the prevalence of anaemia was significantly higher in hospitalised patients compared to outpatients $(68 \%$ vs $16 \%){ }^{6}$

There are several studies assessing the prevalence of anaemia in outpatients, but there is a significant discrepancy in terms of results, ranging from $9 \%{ }^{29}$ and $73 \% .{ }^{12}$ Ott et $\mathrm{al}^{3}$ evaluated the presence of anaemia in patients newly diagnosed with IBD between 2004 and 2009. They found that $32 \%$ of patients had anaemia during this period. In most cases $(75 \%)$, anaemia was present at the time of diagnosis, and the remaining cases were detected during the first year of follow-up. Bergamaschi et $\mathrm{al}^{13}$ reported an overall prevalence of anaemia of $40 \%$ in a population of patients with IBD. The prevalence was higher at diagnosis $(65 \%)$, decreased in the first 4 years after diagnosis, and remained stable thereafter. Finally, children with IBD appear to have an increased risk of anaemia, as shown by the study of Goodhand et $\mathrm{al}^{2}$ where the prevalence of anaemia was $70 \%$ in adolescents and about $40 \%$ in adults.

\section{Diagnosis of anaemia in inflammatory bowel disease}

Statement 5: The presence of iron deficiency must be screened for in all patients with IBD (EL 2) Agreement: $\mathbf{8 0} \%$
Statement 6: The minimum laboratory tests for the diagnosis of anaemia and/or iron deficiency in patients with IBD are: complete blood count, CRP, ferritin and transferrin saturation (EL 3). These parameters must be measured every $3-12$ months, depending on the activity of the disease (remission/activity) (EL 5)

Agreement: $\mathbf{9 0 \%}$

Statement 7: An annual assessment of vitamin B12 and folic acid is recommended in patients with IBD and small bowel disease and/or prior history of surgical resection of the small intestine (EL 4) Agreement: $\mathbf{9 0} \%$

Statement 8: Transferrin saturation (Tsat) $(<16 \%)$ in combination with ferritin is useful in the differential diagnosis of iron deficiency anaemia (ferritin $<30 \mu \mathrm{g} / \mathrm{L}$ ) or chronic disease anaemia (ferritin $>100 \mu \mathrm{g} / \mathrm{L}$ ). Ferritin $30-100$ $\mu \mathrm{g} / \mathrm{can}$ still be associated with iron deficiency in the context of chronic inflammation (EL 2)

Agreement: $100 \%$

Statement 9: The determination of the concentration of soluble transferrin receptors (sTfR) can be useful to detect iron deficiency in patients with anaemia and transferrin saturation $<16 \%$ and ferritin (30 - $100 \mathrm{mg} / \mathrm{L})$ (EL 3)

Agreement: $100 \%$

Statement 10: The TR-F index (sTfR/log serum ferritin) $<1$ is useful to exclude iron deficiency in patients with chronic inflammation anaemia (EL 3) Agreement: $100 \%$

Statement 11: A red cell distribution width (RDW) exceeding 14 has high sensitivity for the diagnosis of iron deficiency (EL 4) Agreement: $90 \%$

\section{Rationale}

The diagnosis of iron deficiency in patients with IBD can be difficult, and there is no gold standard diagnostic. The isolated measurement of haemoglobin is not enough to determine the type of anaemia. Currently there are, however, multiple indexes and markers that, when combined, allow the physician to understand the underlying mechanism of the disease (Fig. 1). ${ }^{41}$

\section{Serum iron concentration}

The serum iron concentration depends on the balance between plasma concentrations and iron deposits and, as such, has significant and frequent fluctuations associated with factors such as the circadian rhythm and intestinal iron absorption..$^{42}$ In addition, the processing of blood samples is subject to many factors that may lead to considerable variation in terms of results. There are still other factors such as menstruation in women, ${ }^{43}$ acute or chronic inflammatory processes (which includes IBD), ${ }^{44}$ malignancies, etc. that can influence the values. ${ }^{45}$ Therefore, serum iron 




Figure 1 - Differential diagnosis for iron deficiency anaemia and chronic disease anaemia

concentration is an index with low specificity and sensitivity for the assessment of iron deficiency in patients with IBD. ${ }^{45}$

\section{Ferritin}

Ferritin is an oligomeric protein capable of storing substantial amounts of iron in a non-toxic, soluble and bioavailable form, thereby serving as an iron reservoir for almost all body cells. ${ }^{46}$ The measurement of ferritin allows for an indirect estimate of body iron stores. Normal values for women are between 15 and $100 \mu \mathrm{g} / \mathrm{L}$ and for men are between 30 and $200 \mu \mathrm{g} / \mathrm{L}$. A serum ferritin level $<15 \mu \mathrm{g} / \mathrm{L}$ is considered as an absolute indicator of iron deficiency. ${ }^{41,47}$

The most common laboratory method for the evaluation of iron deposits in the body is the determination of ferritin. Ferritin despite being a sensitive marker of iron content, is also an acute phase protein and is usually elevated active IBD. During disease activity periods, ferritin is not a sensitive method to assess the presence of iron deficiency. In the presence of inflammation, the lower limit reference ferritin, consistent with normal iron reserves, is expected to be $100 \mu \mathrm{g} / \mathrm{L}$. $^{6,48}$

The interpretation of ferritin levels in patients with active IBD can be difficult because, just like transferrin, this is an acute phase protein, and serum levels may vary in the course of inflammatory processes. The concomitant measurement of inflammatory parameters independent of iron metabolism (erythrocyte sedimentation rate and CRP) is useful for the differential diagnosis. ${ }^{45,47}$ Gasche et al $^{49}$ recommend measuring serum ferritin when screening for anaemia, every 6 to 12 months, in patients in remission or with mild disease, or at least every 3 months in patients with active disease. Once anaemia is diagnosed, the subsequent investigations should include the measurement of serum ferritin, transferrin saturation (Tsat) and CRP. Ferritin values $<30 \mu \mathrm{g} / \mathrm{L}$ in combination with Tsat $<16 \%$ allow a diagnosis of iron deficiency. In the presence of inflammation, the lower limit of serum ferritin is $100 \mu \mathrm{g} / \mathrm{L}$. Thus, the diagnostic criteria for chronic disease anaemia are: serum ferritin $>100 \mu \mathrm{g} / \mathrm{L}$ and Tsat $<16 \%$. If the serum ferritin level is between 30 and $100 \mu \mathrm{g} / \mathrm{L}$ probably there is a combination of chronic disease anaemia and iron deficiency. ${ }^{49}$ The combination of serum ferritin levels and the concentration of transferrin soluble receptors (sTfR) can be useful to detect iron deficiency (STfR increased, low ferritin), inflammation (sTfR and ferritin normal) or mixed conditions (increased STfR, normal ferritin). ${ }^{45}$ The sTfR/log serum ferritin index can be used to exclude iron deficiency, when the ratio is $<1 .{ }^{41}$

\section{Transferrin/total iron binding capacity}

There is an inverse proportional relationship between transferrin (Tf) levels and iron stores. However, Tf levels are also influenced by other factors not related to iron kinetics, 
such as inflammation, infection, malignancy, chronic liver disease, nephrotic syndrome and malnutrition, which may cause a decrease in the values of transferrin whereas pregnancy and oral contraceptives cause an increase of its serum concentration. ${ }^{45,46,50-52}$

\section{Transferrin saturation}

Tsat assess the amount of iron bound to serum Tf (plasma protein responsible for transporting iron from iron stores to the bone marrow). ${ }^{47}$ Tsat levels below $16 \%$ have a relatively high sensitivity $(90 \%)$ for the diagnosis of iron deficiency but relatively low specificity $(40-50 \%)$ as its determination indirectly assesses the use of iron by the bone marrow and does not provide any information about the status of iron stores. ${ }^{46,47}$

\section{Soluble transferrin receptors}

The number of sTfRs reflects haemopoetic cell iron requirements. Contrary to what happens with ferritin and Tf, chronic inflammation and liver injury do not change the levels of sTfR. Therefore, the sTfR level is a fairly reliable parameter for the diagnosis of iron deficiency in patients with IBD. However, increases in STfR concentrations were described in erythropoiesis disorders, as for instance hemolytic anaemia, thalassemia, polycythemia vera, or a reduction of their levels associated with hypoproliferative erythropoiesis conditions, namely aplastic anaemia and anaemia of chronic kidney disease. ${ }^{53-56}$ Therefore, number of STfR is a valid analysis of erythropoietic activity and also a reliable marker of iron deficiency.

\section{Hepcidin/Prohepcidin}

Hepcidin acts as a body 'ferrostatin', by adjusting the amounts of serum iron according to body needs. In chronic disease anaemia there is a reduction of serum iron due to its retention by macrophagocytes and a decreased intestinal absorption of iron, which appears to be caused by an increase in the concentrations of hepcidin (pro-inflammatory cytokines cause an increased expression of the hepcidin gene during inflammatory conditions). Iron deficiency induces a reduction in the production of hepcidin, thus ensuring a greater availability of iron for erythropoiesis. ${ }^{57-59}$ Although hepcidin is strongly implicated in the development of inflammation-associated anaemia, the literature on its specific role in patients with IBD is scarce. The methods used for its quantification are not standardised. ${ }^{60}$

\section{Mean corpuscular volume}

In general, mean corpuscular volume (MCV) is considered a useful indicator of iron deficiency. However, this parameter is difficult to interpret in patients with vitamin B12 and/or folic acid deficiency and/or receiving thiopurines, since these drugs alone increase MCV. ${ }^{61}$

\section{Red cell distribution width}

Red cell distribution width (RDW) is a quantitative measure of the variation in size of the erythrocytes and is equivalent to anisocytosis seen on the blood smear. In blood samples where microcytosis and macrocytosis coexist, these two changes of RDW may cancel each other and originate a 'false' normal RDW. However, the rise in the resulting RDW will identify the error. ${ }^{45}$

A classification of anaemia based on RDW was suggested, which, besides classifying the erythrocyte population in microcytic, normocytic or macrocytic, were stratified as homogeneous (normal RDW; includes etiologies such as a hypoproliferative anaemia, aplastic anaemia, thalassemia) and heterogeneous (increased RDW; includes etiologies such as iron deficiency, vitamin B12 and/or folic acid deficiency and sideroblastic anaemia). ${ }^{45}$ RDW has shown significant increases in patients with IBD compared to healthy controls. A RDW > 14 was positively correlated with sTfR and negatively with Tsat, with a sensitivity of $93 \%$ and a specificity of $81 \%$ for the diagnosis of iron deficiency anaemia. RDW was not significantly correlated with disease activity (since it depends mainly on the erythropoietic activity of the bone marrow and not on the degree of inflammation). ${ }^{61}$ Thus, RDW is a useful parameter to distinguish iron deficiency anaemia from chronic disease anaemia in patients with active IBD.

\section{Percentage of hypochromic cells}

The percentage of hypochromic cells (PHC) assesses the amount of red blood cells with intracellular haemoglobin concentration $<28 \mathrm{~g} / \mathrm{dL}$. Its measurement is a parameter with high sensitivity for iron deficiency, since small changes in the number of erythrocytes with adequate haemoglobin can be detected before a decrease in MCV occurs. ${ }^{62,63}$ Its usefulness to detect iron deficiency anaemia in IBD is limited, in part because the PHC value depends on the total number of erythrocytes, which can vary considerably with the time of storage/processing of blood samples, and also due to the lack of studies investigating its role in IBD. ${ }^{62,63}$

\section{Zinc erythrocyte protoporphyrin}

Zinc erythrocyte protoporphyrin is produced when zinc is incorporated in IX protoporphyrin instead of iron, which occurs when the iron supply for erythropoiesis is decreased. The values of zinc erythrocyte protoporphyrin reflect the severity of iron deficiency, allowing for a distinction between mild iron deficiency (erythrocyte PZ $40-60 \mathrm{mmol} / \mathrm{mol}$ of haemoglobin) and severe iron deficiency (erythrocyte $\mathrm{PZ}>$ $80 \mathrm{mmol} / \mathrm{mol}$ of haemoglobin). ${ }^{63,64}$ In the context of IBD, since zinc deficiency is common, it may be impossible to interpret the levels of zinc erythrocyte protoporphyrin.

\section{Mean reticulocyte volume}

There is evidence that the mean reticulocyte volume $(\mathrm{MCV})$ increases after iron supplementation in patients with iron deficiency and decreases with the development of iron deficient erythropoiesis. This parameter should not, however, be used in clinical practice since the measurement protocol and reference values are not standardised. ${ }^{45}$ 


\section{Reticulocyte haemoglobin content}

The reticulocyte haemoglobin content $(\mathrm{CHr})$ is an indirect measure of the amount of iron available for erythropoiesis in the last 3 - 4 days, also providing information about the response to iron supplementation as it increases within 2 - 4 days after initiation of this therapy. ${ }^{45,65}$ Although there are currently no studies that assess $\mathrm{CHr}$ in patients with IBD, this could be a particularly useful parameter, not in the diagnosis of iron deficiency, but in the evaluation of the response to therapy. ${ }^{45,63,65}$

\section{Immature reticulocyte fraction}

Immature reticulocytes are released into the bloodstream during periods of intense erythropoiesis. Immature reticulocyte fraction (IRF) increases before the amount of total reticulocyte count increases, and it has proved to be useful in the differential diagnosis of anaemia with increased erythropoiesis (increased reticulocyte count; increased IRF), anaemia with reduced erythropoietic activity (decreased reticulocyte count; decreased IFR), and other conditions, such as acute infection/inflammation and myelodysplastic syndromes (reticulocytes decreased/ normal, increased IRF). ${ }^{45,63}$

Although there are studies that evaluated IRF in patients with IBD, some limitations, such as lack of standardisation and reference intervals that depend on the method used, cause IRF to be an indicator of limited use in the evaluation of anaemia in the context of IBD. ${ }^{45}$

\section{Volume distribution width of reticulocytes}

The volume distribution width of reticulocytes (Reticulocyte VD) is a quantitative measure of the variation in the size of reticulocytes. In a study with patients with IBD, the reticulocyte VD was negatively correlated with Tsat and positively correlated with STfR, and showed significantly higher values in patients with iron deficiency anaemia compared with other causes of anaemia. However, the sensitivity and specificity for the diagnosis of iron deficiency were low (60\% and $51 \%$, respectively) which limits the use of this measure. ${ }^{45,63,66}$

\section{Red blood cell size factor}

The red blood cell size factor (RSf) (MCV2x MCVr) is a parameter that evaluates the erythropoietic activity of the bone marrow. It is significantly and positively correlated with Tsat and negatively with STfR in patients with IBD, and has no significant correlation with CRP levels. ${ }^{45,63,67}$

\section{Iron supplementation for the prevention of anaemia in inflammatory bowel disease}

Statement 12: The primary prevention of iron deficiency/ anaemia is achieved by effective control of the underlying IBD (EL 4)

Agreement: $90 \%$
Statement 13: A normal haemoglobin level does not exclude the presence of iron deficiency (EL 2)

Agreement: $\mathbf{9 0} \%$

Statement 14: The recurrence of iron deficiency in a patient with IBD who has presented iron deficiency anaemia is frequent (EL 2)

Agreement: $100 \%$

Statement 15: The use of ferric carboxymaltose, currently available in Portugal, is effective in preventing anaemia in iron deficiency patients with IBD (EL 2) Agreement: $100 \%$

\section{Rationale}

The presence of iron deficiency in the context of IBD is frequent, most often diagnosed in association with anaemia. Although, it is estimated that iron deficiency without anaemia is much more common than anaemia in the context of IBD, there are no guidelines on the subject, nor criteria for diagnosis. Because of this, there are few studies specifically addressing the presence of iron deficiency in IBD, despite iron deficiency being the primary cause of anaemia in patients with IBD. ${ }^{6}$ The reduction in body iron content in these patients is more often associated with digestive tract loss due to activity of the disease and the presence of mucosal damage, although these mechanisms are still poorly documented. ${ }^{61}$ Another cause for iron deficiency is reduced iron ingestion. In patients with IBD, dietary restrictions associated with anorexia are frequent, and therefore may lead to iron deficiency. ${ }^{48}$ The disorders of absorption are less common, but were described with the involvement of the upper gastrointestinal tract (duodenum) in $C D$.

The clinical relevance of anaemia is well established in patients with IBD. Studies have shown that anaemia is associated with reduced quality of life and cognitive skills. ${ }^{68,69}$ The use of iron to prevent anaemia in IBD is indicated to prevent iron deficiency anaemia. In this consensus paper, prevention strategies will be considered according to epidemiological definitions. Primary prevention is defined as a set of actions that aim to prevent the development of anaemia in the population of patients with IBD by removing the causative factors.

In formal terms, to assess the effects of iron on the prevention of anaemia, the study population should be composed of patients with IBD at time of the diagnosis (with active disease or not), who underwent any therapeutic intervention aimed at decreasing the incidence of anaemia. This type of study design has not been undertaken. It could also be acceptable to assess these effects based on interventional studies (where the population were patients with active (BDD), showing a reduction of anaemia in treated patients compared with placebo.

A systematic review of Kulnigg et $\mathrm{al}^{6}$ showed that the presence of anaemia and iron deficiency was associated with more severe disease and greater disease activity (as 
occurred in hospitalised patients). However, there are few studies that relate the control of the activity of IBD with the development of anaemia and iron deficiency. From a mechanistic point of view, the effective control of IBD after a period of disease activity should be associated with decreased development of anaemia/iron deficiency in this population. Still, studies to correlate iron deficiency with primary control of IBD do not exist. A recent publication demonstrated, however, that patients in remission have haemoglobin values significantly higher than those patients who did not achieve this goal. ${ }^{70}$ But, assessing these effects was not the objective (primary or secondary) of any study done in IBD. In the ULTRA 1 and in ACT 1 and 2 studies, differences in presence of anaemia between placebo and interventional group were recorded, but only as side effects. ${ }^{71}$ There are no studies showing that mucosal healing is associated with decreased development of iron deficiency and/or anaemia. However, considering the mechanisms underlying its development, mucosal healing should be considered as a key factor in the development of these conditions.

In secondary prevention, the goal is early identification and correction of conditions. Iron deficiency anaemia develops gradually following iron loss, which results in an inability to adequately regenerate red blood cells. Therefore, the identification of iron deficiency prior to the development of anaemia should be the goal of the assessment in these situations. To attain this goal, periodical analytical evaluations should be performed with complete blood count (haemoglobin, erythrocyte haemoglobin average, average cell volume, reticulocytes, and RDW), evaluation of iron stores (ferritin and transferrin saturation) and assessment of the level of inflammation (though CRP). It was proposed that the assessment should be conducted at least every 12 months in patients with disease in remission, every 6 months in patients with mild disease and every 3 months or more frequently in patients with severe disease. Of course, the scheduling of assessments should be based on the clinical situation, with special focus on symptomatic patients or those with disease activity. ${ }^{72}$

The ECCO also states criteria for the diagnosis of iron deficiency in patients with UC. ${ }^{73}$ Despite no such statements existing for $\mathrm{CD}$, the same reference laboratory parameters can be used. Correction of iron deficiency should be performed early, ${ }^{73}$ however, this proposal was based on iron deficiency in other clinical contexts. The aim of iron supplementation is to prevent the development of anaemia and improve the quality of life of these patients. The mainstay of treatment for iron deficiency depends on the administration of iron being available in various formulations for intravenous and oral supplementation use. The use of oral iron is associated with gastrointestinal side effects that limit effectiveness and tolerance, however, in patients with disease remission it may have less gastrointestinal sideeffects ${ }^{74}$ but those may be confused with complains of disease activity. ${ }^{6}$

The use of intravenous iron is the most effective way to prevent iron deficiency associated with IBD. ${ }^{75}$ Data from randomised studies have shown that the use of intravenous iron is effective for replenishment of iron and prevention of IBD-associated anaemia. ${ }^{76-78}$ Iron sucrose and iron carboxymaltose are also effective in the replenishment of iron, but iron carboxymaltose shown higher efficacy. ${ }^{79}$

Tertiary prevention corresponds to the correction of iron deficiency that may arise after treatment of previously occurred anaemia. The recurrence of iron deficiency in a patient with IBD who had already iron deficiency anaemia is common. The only study assessing this trend showed that, after appropriate treatment of anaemia about $50 \%$ of patients had recurrence of iron deficiency or anaemia in about 10 months and 11 months, respectively. ${ }^{80}$ These data suggest that after the treatment of iron deficiency anaemia in IBD patients, prevention strategies should be established to avoid its recurrence.

Only one study was conducted to evaluate the effectiveness of carboxymaltose iron to prevent recurrence of anaemia in patients with IBD who already received treatment to iron deficiency anaemia. ${ }^{81}$ The administration of iron carboxymaltose after treatment of anaemia proved to be effective and safe in preventing iron deficiency (and anaemia). Recurrence of anaemia occurred in $26.7 \%$ of patients in the treatment group and $39.4 \%$ in the placebo group; also the time to recurrence of anaemia was shorter in the placebo group (4.7 vs 7.6 months).

There are multiple studies with conflicting results concerning the quality of life, however, treated patients globally performed better. ${ }^{82}$

\section{Treatment of iron deficiency anaemia in inflammatory bowel disease}

Statement 16: The treatment of anaemia should be performed in patients with haemoglobin levels below normal (non-pregnant women $\mathrm{Hg}<12$ $\mathrm{g} / \mathrm{dL}$, men $\mathrm{Hg}<13 \mathrm{~g} / \mathrm{dL}$ (EL 2)

Agreement: $100 \%$

Statement 17: Oral and/or IV supplementation is effective in the treatment of iron deficiency anaemia in patients with IBD (EL 1)

Agreement: $100 \%$

Statement 18: Oral iron supplementation may be an option in patients with inactive IBD (clinical and biomarkers) (EL 5) and mild anaemia (Women Hg 10 - 12 g/dL, men Hg 11 - 13 $\mathrm{g} / \mathrm{dL})(E L \mathrm{4})$. Doses up to $100 \mathrm{mg} /$ day of iron are associated with fewer adverse effects and should be preferred (EL 4) Agreement: $100 \%$ 
Statement 19: Supplementation with IV iron (ferric carboxymaltose and iron sucrose) is more effective than oral iron therapy on the increase of haemoglobin and ferritin and is associated with a lower rate of side effects and discontinuation of therapy (EL 1). Therapy with ferric carboxymaltose showed a superior effectiveness and was at least as safe as iron sucrose (EL 2). It is thus the most effective form of treatment of iron deficiency anaemia in IBD (EL 2)

Agreement: $100 \%$

Statement 20: Supplementation with IV iron should be preferred in patients with IBD, particularly in the presence of severe anaemia $(\mathrm{Hg}$ $<10 \mathrm{~g} / \mathrm{dL}$ ), symptomatic anaemia, active bowel disease and inadequate response or intolerance to oral iron therapy (EL 3) Agreement: $100 \%$

Statement 21: The response to iron therapy is considered appropriate if there is an increase of $\mathrm{Hg} \geq 2.0$ $\mathrm{g} / \mathrm{dL}$ or normalization within 4 weeks (EL 3 ). The response to therapy should be evaluated within 4 weeks or earlier in symptomatic patients (EL 5)

Agreement: $\mathbf{9 0 \%}$

\section{Rationale}

The goals of therapy for IBD patients with iron deficiency anaemia are to: treat the underlying cause, limit further losses, reduce malabsorption, avoid blood transfusion in hemodynamically stable patients, relieve symptoms and improve the overall quality of life. ${ }^{47}$ Iron supplementation should be initiated whenever there is iron deficiency anaemia. In the cases where there is iron deficiency without anaemia, the initiation of therapy should be individualised. Although the therapy with oral iron is often used, the variable intestinal absorption of iron, its side effects and low tolerance (leading to discontinuation in approximately $20 \%$ of patients) have led to the increased use of intravenous formulations. ${ }^{49}$

For decades, oral replacement therapy was considered the standard of care, in view of its safety criteria, efficacy and lower costs. Interestingly, the best evidence of the effectiveness of oral iron therapy in IBD comes from headto-head trials with IV iron therapy. ${ }^{83}$ Different formulations are available with varying levels of elemental iron $(33 \%$, ferrous fumarate, $20 \%$ ferrous sulphate, $12 \%$ ferrous gluconate). Three main factors influence the choice of the amount of elemental iron to administer: i) it is highly unlikely that more than $20 \mathrm{mg}$ daily of iron are absorbed by the human intestine, ${ }^{84}$ ii) the well-known clinical intolerance (common to other groups of patients), and iii) the likely tissue toxicity of excess unabsorbed iron in the intestinal mucosa of patients with IBD, which could lead to decompensated disease. ${ }^{85}$ The dose recommended by the Centers for Disease Control and Prevention (CDC) for individuals with iron deficiency anaemia is $60-120 \mathrm{mg} /$ day of elemental iron for therapeutic use and $30 \mathrm{mg} /$ day for prophylactic use. Therapy should be continued for 5 months or at least 3 months after recovery of iron stores. ${ }^{86}$ However, the optimal dose of oral iron to be administered to patients with IBD is not yet established. Due to the common GI adverse effects (about 20\%) some authors have proposed a maximum dose of $100 \mathrm{mg} /$ day in these patients. If therapy with oral ferrous salts is used, response and tolerability should be monitored, and administration should be changed to IV whenever necessary. ${ }^{83}$

The formulations of IV iron available in Portugal include iron sucrose, iron dextran and ferric carboxymaltose (ferric gluconate, isomaltoside and ferumoxytol are not available). The formulations with high stability of ferric carboxymaltose and iron dextran allow the administration of large amounts of elemental iron (1000 mg) in a single dose. The risk of severe hypersensitivity reactions is low, but the formulations of iron dextran and iron sucrose require the administration of a test dose followed by slow infusion. ${ }^{87,88}$ The formulation of ferric carboxymaltose, due to the absence of the risk of hypersensitivity cross-reactions with iron dextran, can be administered without the need for prior testing and rapid infusion in about 15 minutes.

There is still a limited experience with the use of iron dextran (low molecular weight) in IBD, but it was possible to obtain a complete replacement of the deficit in 45 of 50 patients studied (90\%), although only $23(46 \%)$ achieved a complete haematological response, and for that the dose test was required, which led to the prior exclusion of four patients. The total dose may require several hours to be administered, thus conditioning its use in outpatient treatment of IBD. 89

Two randomised controlled studies compared the efficacy and safety of IV iron sucrose and oral iron in patients with IBD. ${ }^{77,78}$ In one study, ${ }^{77}$ among the 91 patients enrolled, more patients in the group of IV iron completed the treatment $(96 \%$ vs $76 \%, p=0.0009)$ and had an increase in haemoglobin above $2.0 \mathrm{~g} / \mathrm{dL}$ (66 \% vs $47 \%$ $p=0.07)$. The second study, ${ }^{78}$ compared the administration of a single dose of iron sucrose $(7 \mathrm{mg} / \mathrm{kg})$ followed by five infusions of $200 \mathrm{mg}$ infusions for 5 weeks compared with oral ferrous sulphate 100 - 200 mg/day for 6 weeks. Fewer patients in the group of IV iron discontinued the therapy due to side effects compared to oral iron (4.5\% vs $20.8 \%$ ), but there was a comparable increase in haemoglobin for both administration routes $(0.25 \mathrm{~g} / \mathrm{L}$ in the IV iron sucrose group vs. $0.21 \mathrm{~g} / \mathrm{L}$ in the oral iron group).

Two randomised studies ${ }^{76,90}$ also showed the effectiveness of ferric carboxymaltose in iron deficiency anaemia in patients with IBD. Kulnigg et $\mathrm{al}^{76}$ compared IV administration of ferric carboxymaltose at the maximum dose of $1000 \mathrm{mg}$ per week until the replenishment of the iron deficit (calculated by the Ganzoni formula) versus oral ferrous sulphate $100 \mathrm{mg}$ twice daily for 12 weeks. At week 12, ferric carboxymaltose was non-inferior to oral iron in increasing haemoglobin $(3.6 \mathrm{~g} / \mathrm{dL} v s 3.0 \mathrm{~g} / \mathrm{dL}, p=$ $0.6967)$. More patients in the oral iron group discontinued 
therapy, and there was no statistically significant difference in the side effect profile between both groups $(p=0.0693)$. In the second study, Evstatiev et al ${ }^{90}$ compared the administration of three infusions of $500 \mathrm{mg}$ or $1000 \mathrm{mg}$ of ferric carboxymaltose with $200 \mathrm{mg}$ of iron sucrose to a maximum of 11 infusions in 485 patients. The calculation of IV iron to be administered was to be done through a more simple and functional formula than the old Ganzoni formula. More patients treated with ferric carboxymaltose achieved a response with an increase in haemoglobin $>2.0 \mathrm{~g} / \mathrm{dL}(65.8$ $\%$ vs $53.6 \%, p=0.004)$ or a correction of anaemia (83.8 vs $75.9 \%, p=0.033$ ) when compared with iron sucrose. After calculation of indirect costs, ferric carboxymaltose apparently more expensive in comparison to the cost per mg of infused iron - proved to be cheaper by $25 \%$. Similarly there was no significant difference in the incidence of side effects in both groups. ${ }^{90}$

A randomised study ${ }^{91}$ compared IV iron isomaltoside 1000 with oral iron sulphate $200 \mathrm{mg} /$ day in the treatment of anaemia in patients with IBD. However, non-inferiority of IV iron isomaltoside in change of haemoglobin to week 8 could not be demonstrated. Actually, there was a trend for oral iron sulphate being more effective in increasing haemoglobin (estimated treatment effect was -0.37 in the IV iron isomaltoside group versus -0.45 in the oral iron sulphate group; $p=0.09$ ). Both treatment groups showed similar safety profiles. More patients in the oral iron group discontinued therapy (16\% vs $11 \%)$, but the proportion of patients discontinuing therapy due to adverse events was comparable between groups ( $3 \%$ vs $2 \%$ ).

A systematic review of prospective and comparative studies of oral iron versus IV iron, which included three studies with a total of 333 patients (203 on IV therapy and 130 on oral therapy) showed that IV iron therapy is significantly superior to oral iron in the increase of haemoglobin levels (mean difference of $0.68 \mathrm{~g} / \mathrm{dL}$ with $\mathrm{Cl} 0.9$ - 12.7) and of ferritin (mean difference of $109.7 \mu \mathrm{g} / \mathrm{L}, \mathrm{Cl} 5.37-214, p=$ $0.04)$. As regards the discontinuation due to side effects, the odds ratio for discontinuation of oral iron was 6.2 compared to IV iron. Both formulations resulted in an improvement of quality of life (SF-36 scale). ${ }^{92}$

Therefore, therapy with IV iron is superior in the increase of haemoglobin and ferritin levels in patients with IBD, although its relevance in clinical practice is still unknown. Therapy with oral iron is associated with more side effects and higher rates of discontinuation. ${ }^{83}$

Recent guidelines ${ }^{49}$ suggest that the preferred route for iron supplementation in IBD is the intravenous administration, considering the more favourable profile of efficacy and side effects. Furthermore, studies in animal models have demonstrated that luminal iron that is not absorbed can cause damage by oxidative stress and exacerbate bowel inflammation. ${ }^{93}$ Absolute indications for intravenous therapy should be considered: (1) moderate to severe anaemia (haemoglobin $<10.5 \mathrm{~g} / \mathrm{dL}$ ) or clearly symptomatic anaemia; (2) previous intolerance to oral iron supplements; (3) inappropriate response to oral iron;
(4) active severe intestinal disease; (5) need for a quick therapeutic response (e.g. surgery in the short term); (6) concomitant therapy with erythropoiesis-stimulating agent; and (7) patient's preference. ${ }^{49,92}$

The erythropoietic response to ferric or haematinic supplementation is considered appropriate if haemoglobin concentration increases by at least $2 \mathrm{~g} / \mathrm{dL}$ or there is a normalization of haemoglobin levels within 4 weeks. Haemoglobin levels should be evaluated within 4 weeks in asymptomatic patients and earlier in symptomatic patients, so that therapeutic adjustments can be made. In treatment with oral iron, levels above $100 \mu \mathrm{g} / \mathrm{L}$ of ferritin are considered adequate. On the contrary, ferritin levels are not useful in the monitoring of intravenous therapy. 47,49

\begin{tabular}{|c|c|}
\hline Statement 22: & $\begin{array}{l}\text { In patients with IBD and anaemia } \\
\text { (haemoglobin }<10 \mathrm{~g} / \mathrm{dL} \text { ) who have not } \\
\text { responded satisfactorily to the therapy with } \\
\text { intravenous iron, the use of erythropoiesis- } \\
\text { stimulating agents (erythropoietin, } \\
\text { darbopoietin) should be considered (EL 2). } \\
\text { The use of erythropoiesis-stimulating agents } \\
\text { should be supplemented with adequate } \\
\text { doses of iron (EL } 2 \text { ). The aim of treatment } \\
\text { is to achieve a level of haemoglobin of } \\
11-13 \mathrm{~g} / \mathrm{dL} \text { using the lowest possible } \\
\text { dose of erythropoiesis-stimulating agents, } \\
\text { considering the potential adverse effects from } \\
\text { values above } 13 \mathrm{~g} / \mathrm{dL}(\mathrm{EL} 3 \text { ) } \\
\text { Agreement: } 90 \%\end{array}$ \\
\hline
\end{tabular}

Statement 23: In patients with extensive ileal resections or under a therapy that may interfere with the metabolism of folic acid, the levels of vitamin B12 and folic acid should be monitored and supplementation should be performed whenever necessary (EL 4)

Agreement: $100 \%$

Statement 24: The use of transfusions of red cell concentrates should be restricted to specific clinical situations, such as acute severe anaemia with hemodynamic instability, severe symptomatic anaemia and/or failure of all other treatments (EL 5)

Agreement: $90 \%$

\section{Rationale}

The percentage of patients with IBD and anaemia responsive to iron therapy reaches $50 \%-80 \% .{ }^{77,78}$ The use of erythropoiesis-stimulating agents (erythropoietin, darbopoietin) showed to be useful in treating anaemia, by diminishing the need for transfusion in patients undergoing surgery, oncological patients and patients with chronic kidney disease; it also showed to improve quality of life. ${ }^{94-98}$ In several studies, co-administration of iron and erythropoiesis-stimulating agents led to response rates from $75-100 \% .^{35,99-102}$

Gasché et al ${ }^{101}$ randomised 40 patients for treatment with erythropoietin or placebo after an initial period 
of intravenous iron. The response was defined as an increase in haemoglobin above $2 \mathrm{~g} / \mathrm{dL}$. The increase of absolute haemoglobin levels was significantly higher in patients receiving erythropoietin $(4.9$ vs $3.3 \mathrm{~g} / \mathrm{dL}, p=$ 0.004 ), but the percentage of responses did not reach a statistically significant value between groups. Schreiber et $\mathrm{al}^{35}$ randomised 34 patients with iron-refractory deficiency anaemia to receive erythropoietin therapy or not. After 12 weeks of treatment, the response (defined as an increase of $\mathrm{Hg}>1 \mathrm{~g} / \mathrm{dL}$ ) was higher in the combined therapy (from 8.8 $\mathrm{g} / \mathrm{dL}$ to $10.5 \mathrm{~g} / \mathrm{dL}$ vs $8.7 \mathrm{~g} / \mathrm{dL}$ to $7.8 \mathrm{~g} / \mathrm{dL}$ ). The percentage of responders was significantly higher in the treatment group ( $82 \%$ vs $24 \%, p=0.002$ ). Since the response to therapy with erythropoiesis-stimulating agents requires adequate iron stores (often diminished in these patients), they should be administered before initiating therapy. ${ }^{49}$

In the different trials in patients with IBD, the doses administered were about $150-300 \mu \mathrm{g} / \mathrm{kg}$ of erythropoietin two to three times per week and $0.9 \mu \mathrm{g} / \mathrm{kg}$ of darbepoietin one time per week..$^{35,100,102}$ There are, however, no studies comparing different dosages of erythropoiesis-stimulating agents. Extrapolating from the studies in oncology and nephrology, the target haemoglobin level should be between 11 - $13 \mathrm{~g} / \mathrm{dL} .{ }^{103,} 104$ These values showed benefits in the physical capacity, quality of life and decreased need for transfusion. ${ }^{105}$

Therapy with erythropoiesis-stimulating agents was associated with a mild to moderate increase in the risk of thrombotic events (deep vein thrombosis, stroke and acute myocardial infarction $)^{94,96,97,106,107}$ and the worsening of hypertension in patients with previous renal disease. ${ }^{108,109}$ These effects occurred mainly in patients with haemoglobin $>13 \mathrm{~g} / \mathrm{dL} .{ }^{96,97,106,107}$ Thus, we suggest regular monitoring of the response to therapy and its discontinuation if it exceeds the above proposed threshold. Evidence on the increase of the dose of erythropoiesis-stimulating agents in nonresponding patients is still limited. ${ }^{109}$

In IBD there is an inappropriate pro-inflammatory response mediated by cytokines such as interleukin (IL) 6 to TNF alpha. Several studies have implicated these cytokines in the genesis of anaemia in IBD. ${ }^{110}$ The mechanism may involve a decreased production or sensitivity to erythropoietin, ${ }^{20}$ inhibition of erythroid precursors ${ }^{13}$ and disruption of the iron metabolism mediated by hepcidin. ${ }^{111}$ Basseri et al ${ }^{112}$ showed a correlation between high levels of IL-6, hepcidin and ferritin and the severity of anaemia.

Although the treatment of anaemia using iron is associated with very favourable responses (50\% - 80\%), the recurrence of anaemia after one year may rise to $50 \%$. ${ }^{80}$ Thus, the treatment of inflammation should precede and accompany other methods of treatment of anaemia and not prevent or replace them, particularly the treatment of iron deficiency.

The use of immunosuppressants has proven effective in treating inflammation anaemia. ${ }^{13,20,111}$ Vijverman et $\mathrm{al}^{36}$ compared two time cohorts (1993 and 2003) of patients with Crohn's disease. The main difference between the two cohorts was the increased use of immunosuppressive therapy (azathioprine) in the second group. The prevalence of mild to moderate anaemia (defined as a level of haemoglobin > $10.5 \mathrm{~g} / \mathrm{dL}$ ) was higher among the patients of the first cohort $(33.8 \%$ vs $16.7 \% p=0.013)$. However, the prevalence of severe anaemia was similar $(6.3 \%$ vs $5.6 \%$ ) in both groups. The treatment with anti-TNF antibodies has proven to be effective in treating anaemia, leading to an increase in erythropoietin levels, in the stimulation of erythroid precursors and in the transition from patterns of inflammation anaemia to iron deficiency anaemia. ${ }^{13}$ Rubin et al, ${ }^{113}$ in a sub-analysis of the CHARM study showed a statistically significant effect of the reduced inflammatory activity on haemoglobin increase $(p<0.001)$ in patients with moderate to severe $C D$ with adalimumab. In the ULTRA 1 study, the improvement of the clinical activity was associated with a statistically significant improvement of haemoglobin. ${ }^{70}$ Katsanos et al ${ }^{114}$ showed in a study with patients with $C D$ and $U C$, with indication for infliximab, that this resulted in increased levels of erythropoietin and soluble transferrin receptors ( $p=0.029$ and $p=0.005)$. These findings achieved normal values after 12 weeks of concomitant therapy with iron. The treatment with infliximab resulted in a decrease of the inflammatory activity, leading to an increase in erythropoiesis, which revealed a latent iron deficiency - a phenomenon that should be anticipated by the physician.

Up to $80 \%$ of the patients with CD showed a variable involvement of the small intestine. Inflammatory activity and previous surgery can reduce the adequate absorption of these elements, leading to a deficiency in the levels of folic acid and vitamin B12, with variable clinical consequences. Bermejo et $\mathrm{al}^{115}$ prospectively evaluated 180 patients with CD and 70 with UC. The prevalence of vitamin B12 and folic acid deficiency in patients with CD and UC was $15.6 \%$ / $22.2 \%$ and $2.8 \%$ / $4.3 \%$, respectively. All patients with anaemia responded to vitamin supplementation, without the need for discontinuation of immunosuppressive therapy. Ileal or ileocolic resection was a risk factor for vitamin B12 deficiency (OR: 2.7) and active inflammatory disease (defined by a Harvey-Bradshaw score $>2$ ) was a risk factor for folic acid deficiency (OR: 2.4). This prevalence was similar to those measured by Yakut et al. ${ }^{116}$

Although a significant percentage of patients with Crohn's disease undergo surgery at some point in their life, deficiency of vitamin B12 is below what could be expected. It is likely that the remaining intestine can adapt, to a certain degree, maintaining the absorption of vitamin B12. As such, only more extensive small intestine resections $(>50-60 \mathrm{~cm}$ ) usually cause a deficit of vitamin B12. ${ }^{115,116}$ In these cases, bacterial overgrowth may also be a contributing factor. ${ }^{117}$ Since absorption of vitamin B12 is potentially compromised, treatment must be administered parenterally.

Although uncommon, folic acid deficiency can result from a combination of poor diet, malabsorption, increased need and use of drugs disturbing the metabolism and absorption of folic acid (methotrexate, sulfasalazine). 
Supplementation must be used as needed.

The use of blood transfusions should not replace the measures previously proposed. Given the high costs and potential adverse effects, ${ }^{118}$ the use of transfusion of red cell concentrates in the treatment of anaemia in IBD should be weighted according to the degree of anaemia, patient's age, comorbidities, hemodynamic stability and degree of bleeding. ${ }^{119}$

\section{CONFLICTS OF INTEREST}

All consensus were supported by OM Pharma Portugal, but there was no scientific interference from OM Pharma, nor any employee of OM Pharma Portugal was allowed in the consensus room. All scientific content is the responsibility of GEDII.

\section{FUNDING SOURCES}

Fernando Magro has served as a speaker for ScheringPlough, Abbott Laboratories, Merck \& Co, UCB Pharma, Ferring, Vifor, AbbVie, Falk, Laboratorios Vitória and OM Pharma.

\section{REFERENCES}

1. Ott C, Scholmerich J. Extraintestinal manifestations and complications in IBD. Nat Rev Gastroenterol Hepatol. 2013;10:585-95.

2. Goodhand JR, Kamperidis N, Rao A, Laskaratos F, McDermott A, Wahed $\mathrm{M}$, et al. Prevalence and management of anemia in children, adolescents, and adults with inflammatory bowel disease. Inflamm Bowel Dis. 2012;18:513-9.

3. Ott C, Liebold A, Takses A, Strauch UG, Obermeier F. High prevalence but insufficient treatment of iron-deficiency anemia in patients with inflammatory bowel disease: results of a population-based cohort. Gastroenterol Res Pract. 2012;2012:595970.

4. Hoivik ML, Reinisch W, Cvancarova M, Moum B, and the IBSEN study group. Anaemia in inflammatory bowel disease: a population-based 10year follow-up. Alimentary pharmacology \& therapeutics. 2014;39:6976.

5. Giannini S, Martes C. Anemia in inflammatory bowel disease. Minerva Gastroenterol Dietol. 2006;52:275-91.

6. Kulnigg S, Gasche C. Systematic review: managing anaemia in Crohn's disease. Aliment Pharmacol Ther. 2006;24:1507-23.

7. Verdon F, Burnand B, Stubi CL, Bonard C, Graff M, Michaud A, et al. Iron supplementation for unexplained fatigue in non-anaemic women: double blind randomised placebo controlled trial. BMJ. 2003;326:1124.

8. Dignass AU, Gasche C, Bettenworth D, Birgegard G, Danese S, Gisbert $\mathrm{JP}$, et al. European consensus on the diagnosis and management of iron deficiency and anaemia in inflammatory bowel diseases. J Crohns Colitis. 2015;9:211-22.

9. Bager P, Befrits R, Wikman O, Lindgren S, Moum B, Hjortswang $H$, et al. The prevalence of anemia and iron deficiency in IBD outpatients in Scandinavia. Scand J Gastroenterol. 2011;46:304-9.

10. Bambach $\mathrm{CP}$, Hill GL. Long term nutritional effects of extensive resection of the small intestine. Aust N Z J Surg. 1982;52:500-6.

11. Beeken WL. Absorptive defects in young people with regional enteritis. Pediatrics. 1973;52:69-74.

12. Beeken WL. Remediable defects in Crohn disease: a prospective study of 63 patients. Arch Intern Med. 1975;135:686-90.

13. Bergamaschi G, Di Sabatino A, Albertini R, Ardizzone S, Biancheri P, Bonetti $E$, et al. Prevalence and pathogenesis of anemia in inflammatory bowel disease. Influence of anti-tumor necrosis factor-alpha treatment. Haematologica. 2010;95:199-205.

14. Burbige EJ, Huang SH, Bayless TM. Clinical manifestations of Crohn's disease in children and adolescents. Pediatrics. 1975;55:866-71.

15. Dumitrescu G, Dranga M, Pintilie IA, Nedelciuc O, Mihai C, Prelipcean CC. The prevalence of anaemia in patients with inflammatory bowel diseases in North-Eastern Romania. Rev Med Chir Soc Med Nat lasi. 2012;116:968-74

16. Dyer NH, Child JA, Mollin DL, Dawson AM. Anaemia in Crohn's disease. Q J Med. 1972;41:419-36.

17. Ebinger M, Leidl R, Thomas S, Von Tirpitz C, Reinshagen M, Adler G, et al. Cost of outpatient care in patients with inflammatory bowel disease in a German University Hospital. J Gastroenterol Hepatol. 2004;19:192-9.

18. Elia PP, Fogaca HS, Barros RG, Zaltman C, Elia CS. Analise descritiva dos perfis social, clinico, laboratorial e antropometrico de pacientes com doencas inflamatorias intestinais, internados no Hospital Universitario Clementino Fraga Filho, Rio de Janeiro. Arquivos de gastroenterologia. 2007;44:332-9.

19. Ershler WB, Chen K, Reyes EB, Dubois R. Economic burden of patients with anemia in selected diseases. Value Health. 2005;8:629-38.
20. Gasche C, Reinisch W, Lochs H, Parsaei B, Bakos S, Wyatt J, et al. Anemia in Crohn's disease. Importance of inadequate erythropoietin production and iron deficiency. Dig Dis Sci. 1994;39:1930-4.

21. Gerasimidis K, Barclay A, Papangelou A, Missiou D, Buchanan E, Tracey $C$, et al. The epidemiology of anemia in pediatric inflammatory bowel disease: prevalence and associated factors at diagnosis and follow-up and the impact of exclusive enteral nutrition. Inflamm Bowel Dis. 2013;19:2411-22.

22. Greenstein AJ, Kark AE, Dreiling DA. Crohn's disease of the colon. II. Controversial aspects of hemorrhage, anemia and rectal involvement in granulomatous disease involving the colon. The Am J Gastroenterol. 1975;63:40-8.

23. Harries AD, Fitzsimons E, Dew MJ, Heatley RV, Rhodes J. Association between iron deficiency anaemia and mid-arm circumference in Crohn's disease. Hum Nutr Clin Nutr. 1984;38:47-53.

24. Hoffbrand AV, Stewart JS, Booth CC, Mollin DL. Folate deficiency in Crohn's disease: incidence, pathogenesis, and treatment. $\mathrm{Br}$ Med J. 1968;2:71-5.

25. Horina JH, Petritsch W, Schmid CR, Reicht G, Wenzl H, Silly H, et al. Treatment of anemia in inflammatory bowel disease with recombinant human erythropoietin: results in three patients. Gastroenterology. 1993;104:1828-31.

26. Krzesiek E, Flis A, Iwanczak B. Ocena czestosci wystepowania niedokrwistosci we wrzodziejacym zapaleniu jelita grubego u dzieci [Frequency of anemia in ulcerative colitis in children]. Polski merkuriusz lekarski. 2012;33:138-42.

27. Lakatos L, Pandur T, David G, Balogh Z, Kuronya P, Tollas A, et al. Association of extraintestinal manifestations of inflammatory bowel disease in a province of western Hungary with disease phenotype: results of a 25-year follow-up study. World J Gastroenterol. 2003;9:23007

28. Morena Lopez F, Gisbert JP. Prevalencia y caracteristicas de la anemia en la enfermedad inflamatoria intestinal. Gastroenterol Hepatol. 2009;32:591-9.

29. Niv Y, Abukasis G. Prevalence of ulcerative colitis in the Israeli kibbutz population. J Clin Gastroenterol. 1991;13:98-101.

30. Oldenburg B, Koningsberger JC, Van Berge Henegouwen GP, Van Asbeck BS, Marx JJ. Iron and inflammatory bowel disease. Aliment Pharmacol Ther. 2001;15:429-38.

31. Pytrus T, Flis A, Iwanczak F, Iwanczak B. Czestosc wystepowania niedokrwistosci u dzieci z nowo rozpoznana choroba LesniowskiegoCrohna [The frequency of anemia in children with newly diagnosed Crohn's disease in children]. Polski merkuriusz lekarski. 2013;34:263-8.

32. Reilly J, Ryan JA, Strole W, Fischer JE. Hyperalimentation in inflammatory bowel disease. Am J Surg. 1976;131:192-200.

33. Rejler M, Tholstrup J, Andersson-Gare B, Spangeus A. Low prevalence of anemia in inflammatory bowel disease: a population-based study in Sweden. Scand J Gastroenterol. 2012;47:937-42.

34. Revel-Vilk S, Tamary H, Broide E, Zoldan M, Dinari G, Zahavi I, et al. Serum transferrin receptor in children and adolescents with inflammatory bowel disease. Eur J Pediatr. 2000;159:585-9.

35. Schreiber S, Howaldt S, Schnoor M, Nikolaus S, Bauditz J, Gasche $\mathrm{C}$, et al. Recombinant erythropoietin for the treatment of anemia in inflammatory bowel disease. N Engl J Med. 1996;334:619-23.

36. Vijverman A, Piront P, Belaiche J, Louis E. Evolution of the prevalence and characteristics of anemia in inflammatory bowel diseases between 
1993 and 2003. Acta Gastroenterol Belg. 2006;69:1-4.

37. Voegtlin M, Vavricka SR, Schoepfer AM, Straumann A, Voegtlin J, Rogler G, et al. Prevalence of anaemia in inflammatory bowel disease in Switzerland: a cross-sectional study in patients from private practices and university hospitals. J Crohns Colitis. 2010;4:642-8.

38. Walker AM, Szneke P, Bianchi LA, Field LG, Sutherland LR, Dreyer NA. 5-Aminosalicylates, sulfasalazine, steroid use, and complications in patients with ulcerative colitis. Am J Gastroenterol. 1997;92:816-20.

39. Werlin SL, Grand RJ. Severe colitis in children and adolescents: diagnosis. Course, and treatment. Gastroenterology. 1977;73:828-32.

40. Wiskin AE, Fleming BJ, Wootton SA, Beattie RM. Anaemia and iron deficiency in children with inflammatory bowel disease. J Crohns Colitis. 2012;6:687-91

41. Oustamanolakis $P$, Koutroubakis IE, Messaritakis I, Niniraki M, Kouroumalis EA. Soluble transferrin receptor-ferritin index in the evaluation of anemia in inflammatory bowel disease: a case-control study. Ann Gastroenterol. 2011;24:108-14.

42. Speck B. Die diurnale Schwankung des Serumeisens und der latenten Eisenbindungskapazitat beim normalen Erwachsenen. Helv Med Acta. 1967;47:S140

43. Zilva JF, Patston VJ. Variations in serum-iron in healthy women. Lancet. 1966;1:459-62

44. Cartwright GE. The anemia of chronic disorders. Semin Hematol. 1966;3:351-75.

45. Oustamanolakis $P$, Koutroubakis IE, Kouroumalis EA. Diagnosing anemia in inflammatory bowel disease: beyond the established markers. J Crohns Colitis. 2011;5:381-91.

46. Gomollon F, Gisbert JP. Anemia and inflammatory bowel diseases. World J Gastroenterol. 2009;15:4659-65.

47. Stein J, Hartmann F, Dignass AU. Diagnosis and management of iron deficiency anemia in patients with IBD. Nat Rev Gastroenterol Hepatol. 2010;7:599-610.

48. Gasche C, Lomer MC, Cavill I, Weiss G. Iron, anaemia, and inflammatory bowel diseases. Gut. 2004;53:1190-7.

49. Gasche C, Berstad A, Befrits R, Beglinger C, Dignass A, Erichsen K, et al. Guidelines on the diagnosis and management of iron deficiency and anemia in inflammatory bowel diseases. Inflamm Bowel Dis. 2007;13:1545-53.

50. Kasvosve I, Delanghe J. Total iron binding capacity and transferrin concentration in the assessment of iron status. Clin Chem Lab Med. 2002;40:1014-8.

51. Hawkins RC. Total iron binding capacity or transferrin concentration alone outperforms iron and saturation indices in predicting iron deficiency. Clin Chim Acta. 2007;380:203-7.

52. Withold W, Neumayer C, Beyrau R, Heins M, Schauseil S, Rick W. Efficacy of transferrin determination in human sera in the diagnosis of iron deficiency. Eur J Clin Chem Clin Biochem. 1994;32:19-25.

53. Punnonen K, Irjala K, Rajamaki A. Serum transferrin receptor and its ratio to serum ferritin in the diagnosis of iron deficiency. Blood. 1997;89:1052-7.

54. Jain S, Narayan S, Chandra J, Sharma S, Jain S, Malhan P. Evaluation of serum transferrin receptor and STfR ferritin indices in diagnosing and differentiating iron deficiency anemia from anemia of chronic disease. Indian J Pediatr. 2010;77:179-83.

55. Beguin Y. Soluble transferrin receptor for the evaluation of erythropoiesis and iron status. Clin Chim Acta. 2003;329:9-22.

56. Hanif E, Ayyub M, Anwar M, Ali W, Bashir M. Evaluation of serum transferrin receptor concentration in diagnosing and differentiating iron deficiency anaemia from anaemia of chronic disorders. J Pak Med Assoc. 2005;55:13-6.

57. Pietrangelo A, Trautwein C. Mechanisms of disease: The role of hepcidin in iron homeostasis--implications for hemochromatosis and other disorders. Nat Clin Pract Gastroenterol Hepatol. 2004;1:39-45.

58. Oustamanolakis P, Koutroubakis IE, Messaritakis I, Malliaraki N, Sfiridaki A, Kouroumalis EA. Serum hepcidin and prohepcidin concentrations in inflammatory bowel disease. Eur J Gastroenterol Hepatol. 2011;23:2628.

59. Arnold J, Sangwaiya A, Bhatkal B, Geoghegan F, Busbridge M. Hepcidin and inflammatory bowel disease: dual role in host defence and iron homoeostasis. Eur J Gastroenterol Hepatol. 2009;21:425-9.

60. Kroot JJ, Kemna EH, Bansal SS, Busbridge M, Campostrini N, Girelli D, et al. Results of the first international round robin for the quantification of urinary and plasma hepcidin assays: need for standardization. Haematologica. 2009;94:1748-52.

61. Gisbert JP, Gomollon F. Common misconceptions in the diagnosis and management of anemia in inflammatory bowel disease. Am J
Gastroenterol. 2008;103:1299-307.

62. Schaefer RM, Schaefer L. The hypochromic red cell: a new parameter for monitoring of iron supplementation during rhEPO therapy. J Perinat Med. 1995;23:83-8

63. Oustamanolakis P, Koutroubakis IE, Messaritakis I, Kefalogiannis G, Niniraki M, Kouroumalis EA. Measurement of reticulocyte and red blood cell indices in the evaluation of anemia in inflammatory bowel disease. $J$ Crohns Colitis. 2011;5:295-300.

64. Scrimgeour AG, Condlin ML. Zinc and micronutrient combinations to combat gastrointestinal inflammation. Curr Opin Clin Nutr Metab Care. 2009;12:653-60.

65. Urrechaga E, Borque L, Escanero JF. Analysis of reticulocyte parameters on the Sysmex XE 5000 and LH 750 analyzers in the diagnosis of inefficient erythropoiesis. Int J Lab Hematol. 2011;33:37-44.

66. Briggs C. Quality counts: new parameters in blood cell counting. Int J Lab Hematol. 2009;31:277-97.

67. Urrechaga E. Clinical utility of the new Beckman-Coulter parameter red blood cell size factor in the study of erithropoiesis. Int J Lab Hematol. 2009;31:623-9.

68. Gasche C. Anemia in IBD: the overlooked villain. Inflamm Bowel Dis 2000;6:142-50.

69. Wells CW, Lewis S, Barton JR, Corbett S. Effects of changes in hemoglobin level on quality of life and cognitive function in inflammatory bowel disease patients. Inflamm Bowel Dis. 2006;12:123-30.

70. Reinisch W, Sandborn WJ, Panaccione R, Huang B, Pollack PF, Lazar A, et al. 52-week efficacy of adalimumab in patients with moderately to severely active ulcerative colitis who failed corticosteroids and/or immunosuppressants. Inflamm Bowel Dis. 2013;19:1700-9.

71. Rutgeerts P, Sandborn WJ, Feagan BG, Reinisch W, Olson A, Johanns $\mathrm{J}$, et al. Infliximab for induction and maintenance therapy for ulcerative colitis. N Engl J Med. 2005;353:2462-76.

72. Gasche C, Evstatiev R, Haas T, Kaser A, Knoflach P, Petritsch W, et al Diagnose und Behandlung von Eisenmangel und Anamie bei chronisch entzundlichen Darmerkrankungen. Konsensus der osterreichischen Arbeitsgruppe fur CED. Z Gastroenterol. 2011;49:627-32.

73. Van Assche G, Dignass A, Bokemeyer B, Danese S, Gionchetti P, Moser $G$, et al. Second European evidence-based consensus on the diagnosis and management of ulcerative colitis part 3: special situations. J Crohns Colitis. 2013:7:1-33.

74. de Silva AD, Tsironi E, Feakins RM, Rampton DS. Efficacy and tolerability of oral iron therapy in inflammatory bowel disease: a prospective, comparative trial. Aliment Pharmacol Ther. 2005;22:1097-105.

75. Leal-Noval SR, Munoz M, Asuero M, Contreras E, Garcia-Erce JA, Llau JV, et al. 2013. Documento Sevilla de Consenso sobre Alternativas a la Transfusion de Sangre Alogenica. Actualizacion del Documento Sevilla. Rev Esp Anestesiol Reanim. 2013;60:263e1-25.

76. Kulnigg S, Stoinov S, Simanenkov V, Dudar LV, Karnafel W, Garcia LC, et al. A novel intravenous iron formulation for treatment of anemia in inflammatory bowel disease: the ferric carboxymaltose (FERINJECT) randomized controlled trial. Am J Gastroenterol. 2008;103:1182-92.

77. Lindgren S, Wikman O, Befrits R, Blom H, Eriksson A, Granno C, et al. Intravenous iron sucrose is superior to oral iron sulphate for correcting anaemia and restoring iron stores in IBD patients: A randomized controlled, evaluator-blind, multicentre study. Scand J Gastroenterol. 2009;44:838-45

78. Schroder O, Mickisch O, Seidler U, de Weerth A, Dignass AU, Herfarth $\mathrm{H}$, et al. Intravenous iron sucrose versus oral iron supplementation for the treatment of iron deficiency anemia in patients with inflammatory bowel disease--a randomized, controlled, open-label, multicenter study. Am J Gastroenterol. 2005;100:2503-9.

79. Reinisch W, Staun M, Bhandari S, Munoz M. State of the iron: how to diagnose and efficiently treat iron deficiency anemia in inflammatory bowel disease. J Crohns Colitis. 2013;7:429-40.

80. Kulnigg S, Teischinger L, Dejaco C, Waldhor T, Gasche C. Rapid recurrence of IBD-associated anemia and iron deficiency after intravenous iron sucrose and erythropoietin treatment. Am J Gastroenterol. 2009;104:1460-7.

81. Evstatiev R, Alexeeva O, Bokemeyer B, Chopey I, Felder M, Gudehus $M$, et al. Ferric carboxymaltose prevents recurrence of anemia in patients with inflammatory bowel disease. Clin Gastroenterol Hepatol. 2013;11:269-77.

82. Befrits R, Wikman O, Blomquist L, Hjortswang $\mathrm{H}$, Hammarlund $\mathrm{P}$, Bajor $A$, et al. Anemia and iron deficiency in inflammatory bowel disease: an open, prospective, observational study on diagnosis, treatment with ferric carboxymaltose and quality of life. Scand J Gastroenterol. 2013:48:1027-32. 
83. Lee TW, Kolber MR, Fedorak RN, van Zanten SV. Iron replacement therapy in inflammatory bowel disease patients with iron deficiency anemia: a systematic review and meta-analysis. J Crohns Colitis. 2012;6:267-75.

84. Rockey DC. Treatment of iron deficiency. Gastroenterology. 2006;130:1367-8.

85. Erichsen K, Ulvik RJ, Grimstad T, Berstad A, Berge RK, Hausken T. Effects of ferrous sulphate and non-ionic iron-polymaltose complex on markers of oxidative tissue damage in patients with inflammatory bowel disease. Aliment Pharmacol Ther. 2005;22:831-8.

86. Recommendations to prevent and control iron deficiency in the United States. Centers for Disease Control and Prevention. MMWR Recomm Rep. 1998;47:1-29.

87. Bailie GR, Clark JA, Lane CE, Lane PL. Hypersensitivity reactions and deaths associated with intravenous iron preparations. Nephrol Dial Transplant. 2005;20:1443-9.

88. Chertow GM, Mason PD, Vaage-Nilsen O, Ahlmen J. Update on adverse drug events associated with parenteral iron. Nephrol Dial Transplant. 2006;21:378-82.

89. Koutroubakis IE, Oustamanolakis P, Karakoidas C, Mantzaris GJ, Kouroumalis EA. Safety and efficacy of total-dose infusion of low molecular weight iron dextran for iron deficiency anemia in patients with inflammatory bowel disease. Dig Dis Sci. 2010;55:2327-31.

90. Evstatiev R, Marteau P, Iqbal T, Khalif IL, Stein J, Bokemeyer B, et al. FERGIcor, a randomized controlled trial on ferric carboxymaltose for iron deficiency anemia in inflammatory bowel disease. Gastroenterology. 2011;141:846-53 e1-2.

91. Reinisch W, Staun M, Tandon RK, Altorjay I, Thillainayagam AV, Gratzer $\mathrm{C}$, et al. A randomized, open-label, non-inferiority study of intravenous iron isomaltoside 1,000 (Monofer) compared with oral iron for treatment of anemia in IBD (PROCEED). Am J Gastroenterol. 2013;108:1877-88.

92. Munoz M, Gomez-Ramirez S, Garcia-Erce JA. Intravenous iron in inflammatory bowel disease. World J Gastroenterol. 2009;15:4666-74.

93. Erichsen K, Hausken T, Ulvik RJ, Svardal A, Berstad A, Berge RK. Ferrous fumarate deteriorated plasma antioxidant status in patients with Crohn disease. Scand J Gastroenterol. 2003;38:543-8.

94. Singbartl G. Adverse events of erythropoietin in long-term and in acute/ short-term treatment. Clin Investig. 1994;72:S36-43.

95. Hung SC, Lin YP, Tarng DC. Erythropoiesis-stimulating agents in chronic kidney disease: what have we learned in 25 years? J Formos Med Assoc. 2014;113:3-10.

96. de Andrade JR, Jove M, Landon G, Frei D, Guilfoyle M, Young DC. Baseline hemoglobin as a predictor of risk of transfusion and response to Epoetin alfa in orthopedic surgery patients. Am J Orthop. 1996;25:53342.

97. Faris PM, Ritter MA, Abels RI. The effects of recombinant human erythropoietin on perioperative transfusion requirements in patients having a major orthopaedic operation. The American Erythropoietin Study Group. J Bone Joint Surg Am. 1996;78:62-72.

98. Moreno Lopez R, Sicilia Aladren B, Gomollon Garcia F. Use of agents stimulating erythropoiesis in digestive diseases. World J Gastroenterol. 2009;15:4675-85.

99. Gasche C, Dejaco C, Reinisch W, Tillinger W, Waldhoer T, Fueger GF, et al. Sequential treatment of anemia in ulcerative colitis with intravenous iron and erythropoietin. Digestion. 1999;60:262-7.

100.Dohil R, Hassall E, Wadsworth LD, Israel DM. Recombinant human erythropoietin for treatment of anemia of chronic disease in children with Crohn's disease. J Pediatr.1998;132:155-9.

101. Gasche C, Dejaco C, Waldhoer T, Tillinger W, Reinisch W, Fueger GF, et al. Intravenous iron and erythropoietin for anemia associated with Crohn disease. A randomized, controlled trial. Ann Intern Med. 1997:126:782 7.

102. Koutroubakis IE, Karmiris $K$, Makreas S, Xidakis C, Niniraki M Kouroumalis EA. Effectiveness of darbepoetin-alfa in combination with intravenous iron sucrose in patients with inflammatory bowel disease and refractory anaemia: a pilot study. Eur J Gastroenterol Hepatol. 2006;18:421-5.

103. Tsubakihara Y, Gejyo F, Nishi S, lino Y, Watanabe Y, Suzuki M, et al. High target hemoglobin with erythropoiesis-stimulating agents has advantages in the renal function of non-dialysis chronic kidney disease patients. Ther Apher Dial. 2012;16:529-40.

104. Phrommintikul A, Haas SJ, Elsik M, Krum H. Mortality and target haemoglobin concentrations in anaemic patients with chronic kidney disease treated with erythropoietin: a meta-analysis. Lancet. 2007;369:381-8.

105. Gisbert JP, Bermejo F, Pajares R, Perez-Calle JL, Rodriguez M, Algaba $A$, et al. Oral and intravenous iron treatment in inflammatory bowel disease: hematological response and quality of life improvement. Inflamm Bowel Dis. 2009;15:1485-91.

106. Laupacis A, Feagan B, Wong C. Effectiveness of perioperative recombinant human erythropoietin in elective hip replacement. COPES Study Group. Lancet. 1993;342:378.

107. Musallam KM, Porter JB, Sfeir PM, Tamim HM, Richards T, Lotta LA, et al. Raised haematocrit concentration and the risk of death and vascular complications after major surgery. Br J Surg. 2013;100:1030-6.

108. Smith KJ, Bleyer AJ, Little WC, Sane DC. The cardiovascular effects of erythropoietin. Cardiovasc Res. 2003;59:538-48.

109. Bokemeyer C, Aapro MS, Courdi A, Foubert J, Link H, Osterborg A, et al. EORTC guidelines for the use of erythropoietic proteins in anaemic patients with cancer: 2006 update. Eur J Cancer. 2007;43:258-70.

110. Keithi-Reddy SR, Addabbo F, Patel TV, Mittal BV, Goligorsky MS Singh AK. Association of anemia and erythropoiesis stimulating agents with inflammatory biomarkers in chronic kidney disease. Kidney Int. 2008;74:782-90.

111. Zhao N, Zhang AS, Enns CA. Iron regulation by hepcidin. J Clin Invest. 2013;123:2337-43

112. Basseri RJ, Nemeth E, Vassilaki ME, Basseri B, Enayati $P$, Shaye $O$, et al. Hepcidin is a key mediator of anemia of inflammation in Crohn's disease. J Crohns Colitis. 2013;7:e286-91.

113. Rubin DT, Mulani P, Chao J, Pollack PF, Bensimon AG, Yu AP, et al. Effect of adalimumab on clinical laboratory parameters in patients with Crohn's disease: results from the CHARM trial. Inflamm Bowel Dis. 2012;18:818-25.

114. Katsanos K, Cavalier E, Ferrante M, Van Hauwaert V, Henckaerts L, Schnitzler $F$, et al. Intravenous iron therapy restores functional iron deficiency induced by infliximab. J Crohns Colitis. 2007;1:97-105.

115. Bermejo F, Algaba A, Guerra I, Chaparro M, De-La-Poza G, Valer P, et al. Should we monitor vitamin B12 and folate levels in Crohn's disease patients? Scand J Gastroenterol. 2013;48:1272-7.

116. Yakut M, Ustun Y, Kabacam G, Soykan I. Serum vitamin B12 and folate status in patients with inflammatory bowel diseases. Eur J Intern Med 2010;21:320-3

117. Mullin GE. Micronutrients and inflammatory bowel disease. Nutr Clin Pract. 2012;27:136-7.

118. Garcia-Erce JA, Gomollon F, Munoz M. Blood transfusion for the treatment of acute anaemia in inflammatory bowel disease and other digestive diseases. World J Gastroenterol. 2009;15:4686-94.

119. Alter HJ, Klein HG. The hazards of blood transfusion in historical perspective. Blood. 2008;112:2617-26. 